\title{
Axin induces cell death and reduces cell proliferation in astrocytoma by activating the $\mathbf{p 3}$ pathway
}

\author{
LI-YING ZHANG ${ }^{*}$, JING YE*, FENG ZHANG, FAN-FAN LI, HANG LI, \\ YU GU, FANG LIU, GUANG-SHENG CHEN and QING LI
}

\begin{abstract}
State Key Laboratory of Cancer Biology and Department of Pathology, Xijing Hospital, Fourth Military Medical University, Xi'an 710032, P.R. China
\end{abstract}

Received January 30, 2009; Accepted April 14, 2009

DOI: 10.3892/ijo_00000309

\begin{abstract}
Astrocytic tumors are the most common brain tumors with various genetic defects. As a tumor suppressor gene, Axin could control cell death and growth. Axin possesses a separate domain that directly interacts with p53 and regulates the activity of p53 pathway. Our aims were to elucidate the effects of Axin on the progression of astrocytoma. We examined the expression of Axin in 96 cases of astrocytoma using immunohistochemistry. The apoptotic index, proliferactive acitivity and the expression levels of p53 and its downstream genes, p21 and Cyclin D1, were evaluated in the C6 astrocytoma cells with overexpression or silencing of Axin. The results showed the levels of Axin correlated significantly inversely with the grades of astrocytoma $(\mathrm{R}=-0.286, \mathrm{P}<0.05)$ and correlated negatively with $\mathrm{Ki}-67$ labeling index $(\mathrm{R}=-0.227$, $\mathrm{P}<0.05)$. Overexpression of Axin in C6 cells induces cell death, and reduces the cell proliferation, up-regulates the expression of p53. Silencing of Axin reduces p53 expression. The p53 inhibitor, pifithrin- $\alpha$, was able to counteract the effect of Axin in C6 cells. Our data demonstrate that the expression of Axin is associated negatively with the progression of astrocytoma. In conclusion, Axin induces cell death and reduces cell proliferation, partially by activating the p53 pathway in astrocytoma cells. This knowledge is helpful in understanding the role of Axin in the progression of astrocytoma.
\end{abstract}

\section{Introduction}

Astrocytomas are the most common primary brain tumors and classified according to their histologic characteristics in

Correspondence to: Dr Qing Li, State Key Laboratory of Cancer Biology and Department of Pathology, Xijing Hospital, Fourth Military Medical University, Xi'an 710032, P.R. China

E-mail: liqing@fmmu.edu.cn

${ }^{*}$ Contributed equally

Key words: axin, astrocytoma, proliferation, apoptosis, p53 low-grade astrocytomas and high-grade tumors (including glioblastoma multiforme, GBM). Modern molecular genetic analyses have revealed that the progression of astrocytic tumors results from accumulating inactivation of different tumor suppressor genes and/or amplification of certain oncogenes (1-3).

Axin was originally identified from the characterization of the Fused locus (4). Molecular analysis revealed that Axin is a master scaffold protein within the cell $(5,6)$. Axin utilizes different domains for its distinct roles in different signaling pathway. To date, Axin has been implicated in at least four different signaling pathways: the Wnt signaling pathways, the stress-activated protein kinase/Jun N-treminal kinase (SAPK/JNK), transforming growth factor $\beta$ (TGF- $\beta$ ) and p53 signaling pathways (4,5,7-11). Axin acts as a possible mediator for cross-talk in these signaling pathways. Recent data showed that Axin formed a ternary complex with homeodomain-interacting protein kinase-2 (HIPK2) that is bound to p53 (11-13), which is involved in UV-induced p53dependent apoptosis via phosphorylation of Ser46 of p53 in 293 cells (11). Decreased Axin expression has been reported to correlate with tumor differentiation of oesophageal squamous cell carcinoma (14), whereas high Axin levels may induce cell apoptosis $(11,15)$. We hypothesized that Axin expression may correlate with the progression of astrocytoma. The question of how Axin may be involved in the regulation of progression of astrocytoma cells still need to be addressed. Therefore, in this study we examined the expression levels of Axin in low and high grades astrocytomas and analyzed the relationship between Axin expression and the clinical pathology. Furthermore, we treated the C6 astrocytoma cells with overexpression or silencing of Axin and explored the effect of axin on cellular proliferation and apoptosis and the expression of p53 and its downstream genes, p21 and Cyclin D1 to analyze the mechanisms and molecules of Axin involved in the astrocytoma progression in vitro.

\section{Patients and methods}

Patients and tumors. We obtained 96 surgically removed astrocytoma tissues from the Xijing Hospital, the affiliated hospital of the Fourth Military Medical University, China. All samples were pathologically confirmed astrocytoma or glioblastoma multiforme (GBM, Grade IV). Patients were 
Table I. Biopsy specimens.

\begin{tabular}{|c|c|c|c|c|c|}
\hline \multirow[b]{2}{*}{ Histopathological diagnosis } & \multirow[b]{2}{*}{ Total case no. } & \multirow[b]{2}{*}{ Male } & \multirow[b]{2}{*}{ Female } & \multicolumn{2}{|c|}{ Age } \\
\hline & & & & Median & Range \\
\hline WHO Grade II & 49 & 30 & 19 & 31 & $3-69$ \\
\hline WHO Grade III & 31 & 17 & 14 & 45 & $17-65$ \\
\hline WHO Grade IV & 16 & 9 & 7 & 53 & $36-66$ \\
\hline
\end{tabular}

2007 WHO Grade II includes pilomyxoid astrocytoma, pleomorphic xanthoastrocytoma and diffuse astrocytoma; WHO Grade III includes anaplastic astrocytoma and WHO Grade IV includes glioblastoma, giant cell glioblastoma and gliosarcoma.

3-69 years of age, and the mean age was 36 years (56 males and 40 females) (Table I). These tumors were classified as Grade II, III and IV according to the classification system of CNS (2007) of World Health Organization (WHO), including 49 cases of Grade II, 31 cases of Grade III, and 16 cases of Grade IV. Because WHO Grade I astrocytoma were biologically and genetically distinct from diffuse astrocytomas and virtually never progress to higher grades, WHO Grade I astrocytoma were not included in our study. Tissue specimens had previously been fixed in $10 \%$ buffered formalin and embedded in paraffin for routine histological examination.

Immunohistochemistry. Immunohistochemistry was carried out as previously described (16). Briefly, the deparaffinized and rehydrated slides were blocked with with $20 \mathrm{ml} / \mathrm{l}$ fetal calf serum for $30 \mathrm{~min}$ to reduce non-specific binding. Then the anti-Axin antibody (1:200; Santa Cruz, USA) and antiKi-67 antibody (1:200; NeoMarkers, USA) were applied to the sections and incubated at $4^{\circ} \mathrm{C}$ overnight. The breast cancers were used the positive control of Axin and Ki-67. Negative controls were obtained by replacing the primary antibody with non-immune mouse or rabbit serum. The sections were subsequently incubated with the second antibody (Dako, Denmark) at $37^{\circ} \mathrm{C}$ for $40 \mathrm{~min}$, and stained with $\mathrm{DAB}-\mathrm{H}_{2} \mathrm{O}_{2}$ for 5-10 min and counterstained with hematoxylin. The slides were independently evaluated by two observers. Specimens containing $\geq 5 \%$ stained tumor cells were considered positive and $<5 \%$ were considered negative.

For the immuno-fluorescent analysis, cells grew on the glass cover slides to $60 \%$ confluency. Some cells were treated with pifithrin- $\alpha(30 \mu \mathrm{M} / \mathrm{ml})$ or Axin siRNA for $24 \mathrm{~h}$, and fixed with $4 \%$ paraformaldehyde. The TRITC or FITC labeled secondary antibodies were used, and the nuclei stained with Hoechst 33258 (Sigma, USA) for $10 \mathrm{~min}$. The slides were examined by fluorescence E-1000 microscopy (Nikon, Japan).

Cell culture and transfection. C6 astrocytoma cells were maintained in RPMI-1640 media supplemented with $10 \%$ fetal bovine serum (FBS) at $37^{\circ} \mathrm{C}, 5 \% \mathrm{CO}_{2}$. The cells were transfeced with pCMV-HA and pCMV-HA-Axin (gift from Dr Sheng-Cai Lin) using Lipofectamine 2000 (Invitrogen, USA). To investigate the roles of p53 in the cells overexpressing Axin, the transfected C6 astrocytoma cells were treated with the specific p53 inhibitor pifithrin- $\alpha$ (PFT- $\alpha$; Sigma) for $24 \mathrm{~h}$. To determine the roles of Axin in the apoptosis and cell proliferation, siRNA specific to Axin (Genepharma, USA) were used to knockdown the endogenous Axin as previously described (17). To establish the C6 astrocytoma cells stably expressing Axin gene, cells were separately transfected with the plasmid pIRES2-EGFP (C6-EGFP) or pIRES2-EGFP-Axin (C6-Axin). The G418resistant clones were grown in a media containing G418 until the cells stably expressing Axin gene appeared (18).

Growth curve assay, flow cytometric analysis and colony formation analysis. For the growth curve assay (MTT methods), C6 cells were plated in a 96-well plate at a density of 600 cells per well, and incubated in a humidified $5 \% \mathrm{CO}_{2}$ at $37^{\circ} \mathrm{C}$. At $1,3,5$, and 7 days, to cells were added methyl thiazolyl tetrazolium (MTT) $20 \mu 1$ per well. After $4-h$ incubation, the supernatants were removed and $150 \mu 1$ of dimethyl sulfoxide (DMSO) was added to each well and swirled for $10 \mathrm{~min}$ to solubilize crystals, and the absorbance at $490 \mathrm{~nm}$ was measured.

For analysis of cell cycles, $\sim 1 \times 10^{6}$ cells were washed twice with PBS and pelleted at $1,000 \mathrm{x} \mathrm{g}$ for $5 \mathrm{~min}$. Cells were resuspended in ice-cold $75 \%$ ethanol and stained with propidium iodide (PI) followed by analysis of flow cytometry.

One hundred cells were evenly seeded in a 6-well plate in each group and cultured 2-3 weeks in a humidified atmosphere, with $5 \% \mathrm{CO}_{2}$, at $37^{\circ} \mathrm{C}$. The colonies were fixed and stained with Giemsa, and counted under a microscope.

Apoptosis analysis. TUNEL method was used in apoptosis analysis with the apoptosis detection kit (Boster, China) according to the manufacturer's protocol. Briefly, cells were fixed with $4 \%$ paraformaldehyde for $30 \mathrm{~min}$. After washing with $\mathrm{PBS}$, the sections were digested with proteinase $\mathrm{K}$ for 3 min. Sections were labeled with TdT and DIG-d-UTP for $2 \mathrm{~h}$ at $37^{\circ} \mathrm{C}$, and blocked with the blocking reagents at room temperature for $30 \mathrm{~min}$. The anti-Dig-antibody were applied to the cells and incubated at $37^{\circ} \mathrm{C}$ for $30 \mathrm{~min}$. After washing with PBS, sections were incubated with SABC (Boster) at $37^{\circ} \mathrm{C}$ for $60 \mathrm{~min}$, and visualized with $\mathrm{DAB}$, and counterstained with hematoxylin. The apoptotic cells in five different fields were counted and the apoptotic index was calculated as the ratio of apoptotic cells for total cells. 
Table II. Primer sequences and real-time RT-PCR conditions.

\begin{tabular}{|c|c|c|c|}
\hline Amplicon & Primer $\left(5^{\prime}-3^{\prime}\right)$ & Product size (bp) & $\mathrm{Tm}$ \\
\hline \multirow[t]{2}{*}{ B-actin } & P1-5'-GGAGATTACTGCCCTGGCTCCTA-3' & 150 & 64.9 \\
\hline & P2-5'-GACTCATCGTACTCCTGCTTGCTG-3' & & 64.6 \\
\hline \multirow[t]{2}{*}{ Axin } & P1-5'-CAGTAGCGTGGATGGAAT-3' & 113 & 50.6 \\
\hline & P2-5'-AAGTGCGAGGAATGTGAG-3' & & 50.5 \\
\hline \multirow[t]{2}{*}{ Cyclin D1 } & P1-5'-AGGAGCAGAAGTGCGAAGA-3' & 196 & 55.5 \\
\hline & P2-5'-GGGCGGATAGAGTTGTCAGT-3' & & 56.5 \\
\hline \multirow[t]{2}{*}{$\mathrm{P} 21$} & P1-5'-CAAAGTATGCCGTCGTCTGT-3' & 110 & 56.0 \\
\hline & P2-5'-CAAAGTATGCCGTCGTCTGT-3' & & 56.2 \\
\hline \multirow[t]{2}{*}{ P53 } & P1-5'-GCGTTGCTCTGATGGTGA-3' & 232 & 55.1 \\
\hline & P2-5'-CAGCGTGATGATGGTAAGGA-3' & & 56.6 \\
\hline
\end{tabular}

Real-time RT-PCR analysis. Total cellular RNA was extracted with TRIzol Reagent (Invitrogen). Total cellular RNA was reverse transcribed with RNA reverse transcriptal PCR Kit (Takara, Japan), according to the manufacturer's protocol. The levels of mRNA were analyzed by real-time PCR performed with the Bio-Rad iQ4 Multicolor Real-time iCycler (Bio-Rad Laboratories, Hercules, CA, USA). The primers for Axin, p53, p21 and Cyclin D1 are listed in Table II. Amplification products were verified by agarose gel electro-phoresis and melting curves. The levels of mRNA were normalized internally to $\beta$-actin expression, accounting for differences in primer efficiencies (19).

Western immunoblot analysis. C6 cells were collected at $1,000 \times \mathrm{g}$ for $3 \mathrm{~min}$ and washed with PBS. The cells pellet was resuspended in lysis buffer $(0.1 \%$ SDS, $62.5 \mathrm{mM}$ Tris$\mathrm{HCl}$, pH $8.510 \%$ glycerol, $1 \mathrm{mM}$ phenylmethylsulfony 1 fluoride (PMSF), $1 \mu \mathrm{g} / \mathrm{ml}$ pepstatin A, $1 \mu \mathrm{g} / \mathrm{ml}$ leupeptin, and $5 \mu \mathrm{g} / \mathrm{ml}$ aprotinin) and sonicated for $10 \mathrm{sec}$, followed by centrifugation at $12,000 \times \mathrm{g}$ for $10 \mathrm{~min}$. Protein concentrations were determined with the protein quantity kit (Bio-Rad Laboratories). An equal amount of protein $(20 \mu \mathrm{g})$ was separated by SDS-polyacrylamide gels, and transferred to PVDF membranes. The membranes were blocked with 5\% skim-milk in TBST at room temperature for $1 \mathrm{~h}$. The antibodies of Axin (A-0481 Sigma), p53 (Santa Cruz), p21 and Cyclin D1 (ABZOOM, USA) were used to detect the protein levels in total cell lysates. The intensity of B-actin immunostaining was used as internal loading control.

Statistical analysis. Analyses were carried out using SPSS11.5 software. The Pearson or Spearman's correlation test was used to access the relationship of the expression levels of Axin with the clinicopathologic alterations of astrocytoma. The Mann-Whitney U test and the Kruskal-Wallis test were used to analyze the results of real-time RT-PCR, flow cytometry, MTT, and apoptosis. P-values $<0.05$ were considered statistically significant.
Table III. The expression of Axin in 96 cases of astrocytoma.

\begin{tabular}{lrrrr}
\hline \multicolumn{4}{c}{ Axin expression } & \multicolumn{2}{c}{ P-value } \\
& $(-)$ & $(+)$ & & \\
\hline Grades & & & & \\
II & 26 & 23 & & \\
III & 23 & 8 & $\mathrm{R}=-0.286^{*}$ & $\mathrm{P}<0.05$ \\
IV & 14 & 2 & & \\
& & & & \\
Sex & & & & \\
Female & 22 & 18 & $\mathrm{R}=-0.189$ & $\mathrm{P}>0.05$ \\
Male & 41 & 15 & & \\
& & & & \\
Age & & & & \\
440 & 34 & 17 & $\mathrm{R}=0.023$ & $\mathrm{P}>0.05$ \\
$>40$ & 29 & 16 & & $\mathrm{P}>0.05$ \\
& & & & \\
Ki-67 labeling index & & & & \\
$\leq 5 \%$ & 33 & 25 & $\mathrm{R}=-0.227^{*}$ & $\mathrm{P}<0.05$ \\
$>5 \%$ & 30 & 8 & & \\
Location & & & & \\
Frontoparietal & & & & \\
Cerebral ventricle & 5 & 8 & & \\
Temproparietal & 13 & 7 & $\mathrm{R}=0.008$ & \\
Cerebellum & 12 & 3 & & \\
Others & 11 & 7 & & \\
& & & \\
\end{tabular}

\section{Results}

Axin expression correlated with reduced cellular activity in astrocytoma. The immunohistochemistry was employed to investigate the expression of Axin and Ki-67 in the astrocytoma (Fig. 1). As shown in Table III, 33 cases in the 


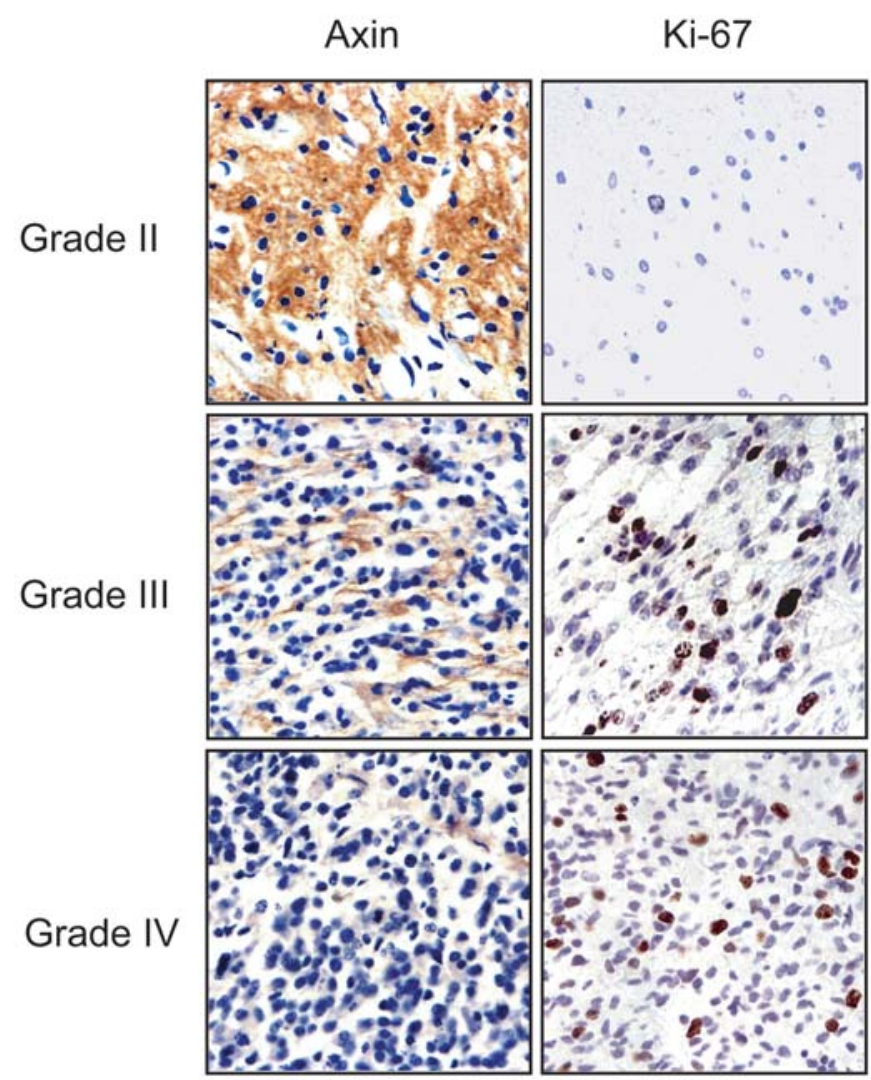

Figure 1. Immunohistochemical staining of Axin and Ki-67 in astrocytoma. The localization of Axin was preserved in both cytoplasma and nuclei, and the expression level of Axin was lower in high-grade astrocytoma compared to low-grade astrocytoma (left panel); Ki-67 was expressed in nuclei, and the expression of Ki-67 was lower in low-grade astrocytoma compared to the high-grade astrocytoma (right panel). The expression of Axin was negatively correlated with the grade of astrocytoma $\left(\mathrm{R}=-0.286 ;{ }^{*} \mathrm{P}<0.05\right)$.

96 samples of astrocytoma showed Axin positive expression (34.4\%). 23 cases of 49 Grade II samples (46.9\%), 8 of 31 Grade III samples (25.8\%), 2 of 16 Grade IV samples (12.5\%) showed Axin positive staining. The Spearman's correlation test revealed that Axin positive expression was significantly inversely correlated with the grades of astrocytoma $(R=-0.286$; $\mathrm{P}<0.05)$.

The correlative analysis between Axin expression and the clinicopathologic characteristics of patients with astrocytoma is summarized in Table III. Axin immunoactivity was correlated negatively with Ki-67 labeling index $(\mathrm{R}=-0.227$, $\mathrm{P}<0.05)$. However, the expression level of Axin did not differ significantly by age $(\mathrm{P}>0.05)$, sex $(\mathrm{P}>0.05)$, and location $(\mathrm{P}>0.05)$.

Axin induces apoptosis, and inhibits proliferative activity of astrocytoma cells. To determine the role of Axin in the astrocytoma, C6 cells were transfected with pCMV5 vector containing Axin. The expression of Axin was detected using immunoblotting, and the apoptotic cells were detected by TUNEL staining. As shown in the Fig. 2A and B, apoptotic index of cells with overexpressed Axin significantly increased compared to the pCMV5 group and the blank control $(\mathrm{P}<0.01)$. The cells with Axin overexpression were shrunken and the nuclei were condensed (Fig. 2A and C). These data indicated
A
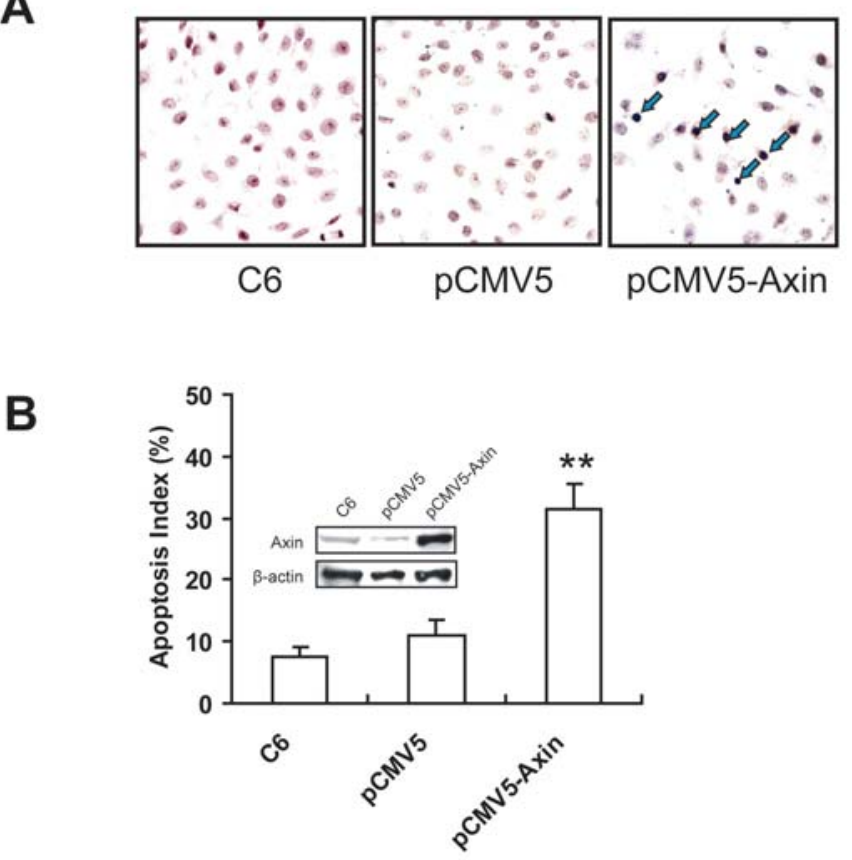

\section{C}

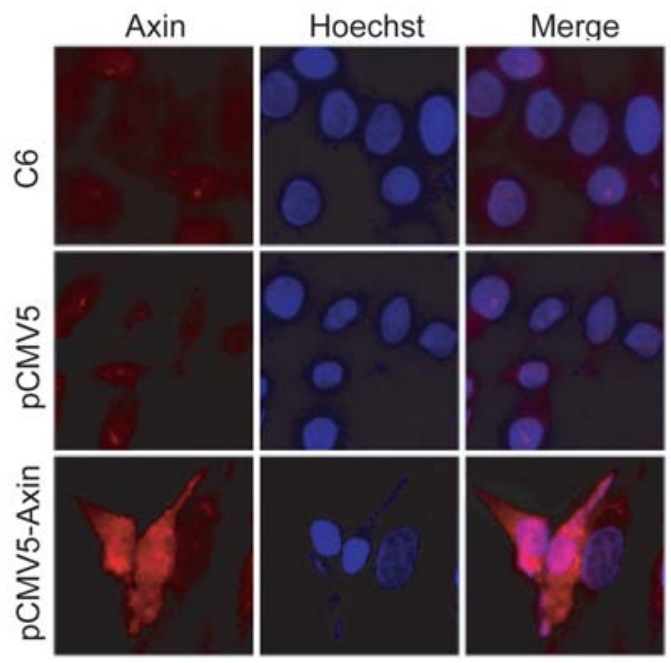

Figure 2. Axin induced apoptosis in C6 astrocytoma cells. After transfection for $48 \mathrm{~h}$, the expression of Axin was detected using immunoblotting, and the apoptosis were examined using TUNEL staining and Hoechst 33258. (A) Apoptosis was detected by TUNEL staining. After transfection with Axin, the nuclei of apoptotic C6 cells became condensed and dark. (B) The apoptosis index of C6 transfected with Axin (33.2 $\pm 4.2 \%)$ was significantly increased compared to C6-pCMV5 $(10.79 \pm 2.6 \%)$ and C6 cells $(7.8 \pm 1.6 \%)$. (C), The nuclei (blue) of cells with overexpression of axin (red) are condensed. $\mathrm{n}=3 ;{ }^{* *} \mathrm{P}<0.01$.

that overexpression of Axin induced cell death in the astrocytoma cell line.

To determine the involvement of Axin in the astrocytoma cell growth, C6 astrocytoma cells were transfected with pIRES2-EGFP-Axin, which could express both Axin and EGFP separately. The cells stably expressing Axin were established by G418 selection. The siRNA specific for Axin was introduced to knockdown Axin expression. The expression levels of Axin was detected using immunoblotting, and the cell cycles were examined by flow cytometry analysis (Fig. 3A). The results indicated that overexpression of Axin 
A

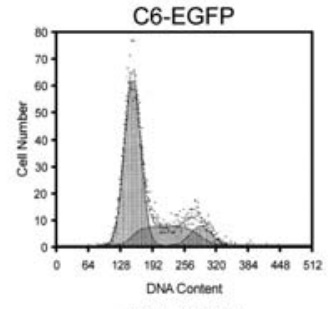

NC SiRNA
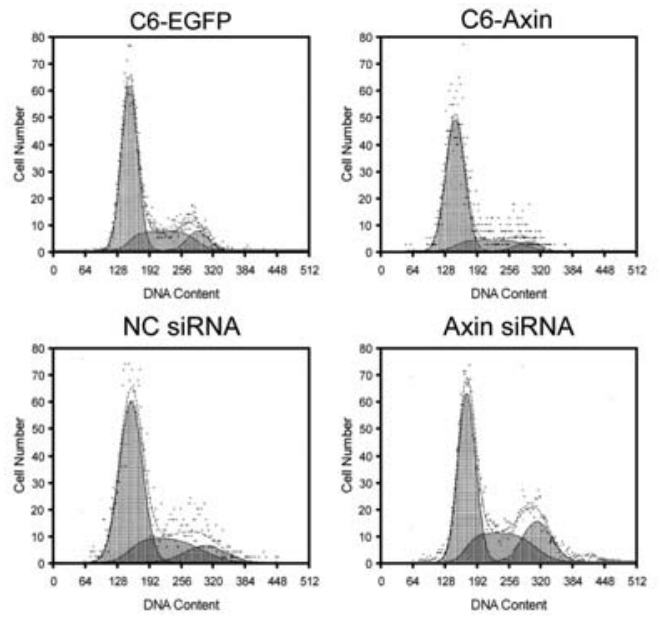

Axin siRNA

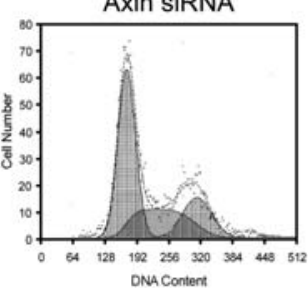

B
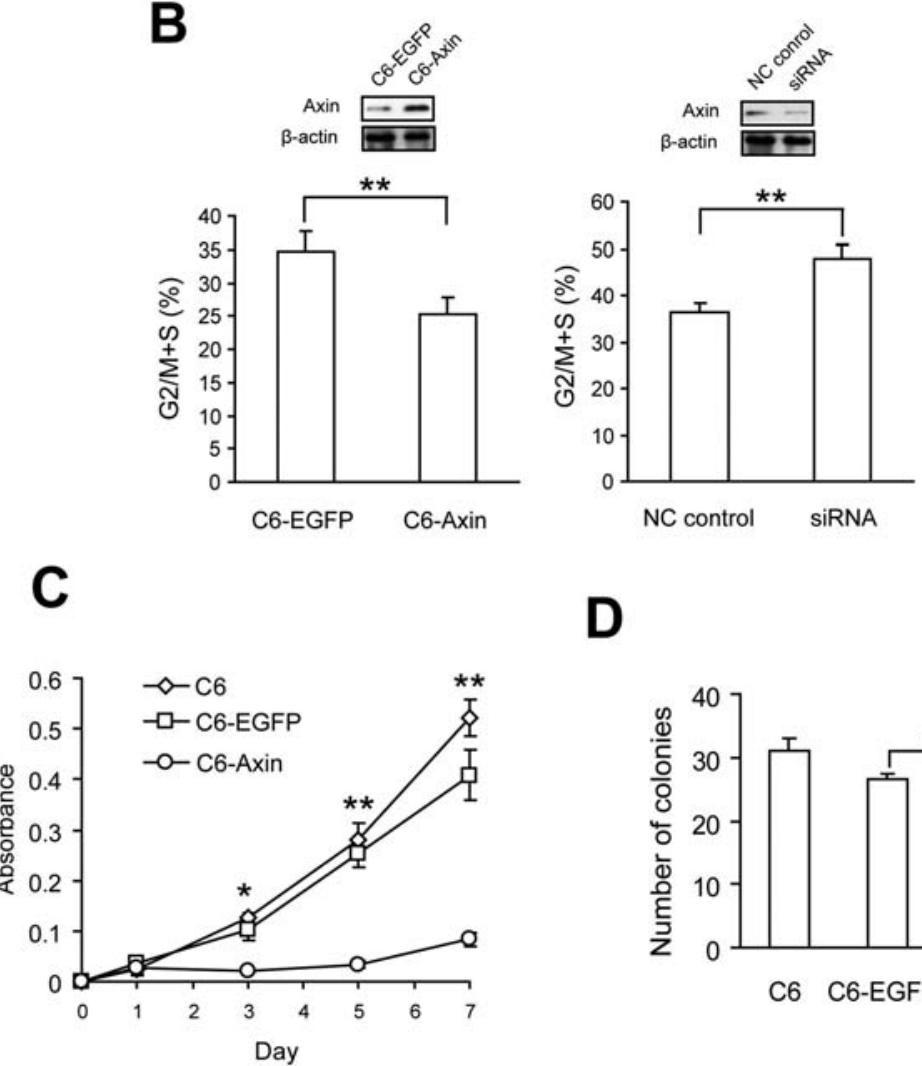

D

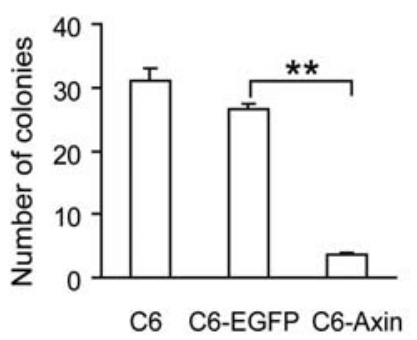

Figure 3. Axin reduces cell proliferative activity in C6 cells. (A) The cell cycle was analyzed by flow cytometry according to DNA content. (B) The percentage of G2/M + S-phase cells was lower in C6 cells transfected with pIRES-EGFP-Axin (C6-Axin) compared to C6 cells transfected with pIRES2EGFP (C6-EGFP). Furthermore, the percentage of G2/M + S-phase cells in C6 cells transfected with Axin siRNA was higher compared to the C6 cells with negative control siRNA (NC siRNA). The expression levels of Axin are shown in the upper panel. (C) The MTT assay indicated that the growth rate of C6Axin group was significantly lower than C6-EGFP and C6 groups. (D) The colony-forming ability was markedly reduced in C6-Axin group compared with the C6-EGFP group ( $3.5 \pm 0.5$ clones/100 cells versus $31 \pm 2$ clones $/ 100$ cells $) . n=3 ;{ }^{*} \mathrm{P}<0.05 ;{ }^{* *} \mathrm{P}<0.01$.

could reduce the distribution of $\mathrm{G} 2 / \mathrm{M}+\mathrm{S}$-phase cells ( $25.2 \%$ versus $34.6 \%, \mathrm{P}<0.01$ ), and led to $\mathrm{G} 1$-phase cell cycle arrested (Fig. 3B). Furthermore, knockdown of Axin in C6 cells could increase the distribution of $\mathrm{G} 2 / \mathrm{M}+\mathrm{S}$-phase cells $(48.0 \%$ versus $36.3 \%, \mathrm{P}<0.01)$.

In order to investigate the proliferation inhibitory effect of Axin on astrocytoma cells, MTT assay and colony-forming ability experiments were used. MTT assay results showed that the level of proliferation in C6 cells overexpressing Axin was significantly lower than that of C6 cells or C6 cells transfected with pIRES2-EGFP $(\mathrm{P}<0.05$ at days 3, 5 and 7)
(Fig. 3C). Similarly, the colony-forming ability markedly reduced in the cells overexpressing Axin compared with the C6 cell transfected with EGFP ( $3.5 \pm 0.5$ clones/ 100 cells versus $31 \pm 2$ clones $/ 100$ cells, $\mathrm{P}<0.01$ ) (Fig. 3D). These results suggested that Axin could inhibit the proliferative activity of astrocytoma cells.

Axin activates the $p 53$ pathway in C6 astrocytoma cells. We next assessed the effect of Axin on the expression of p53 and its downstream genes, p21 and Cyclin D1, which are known to regulate apoptosis and cell cycle distribution (20-22). 
A
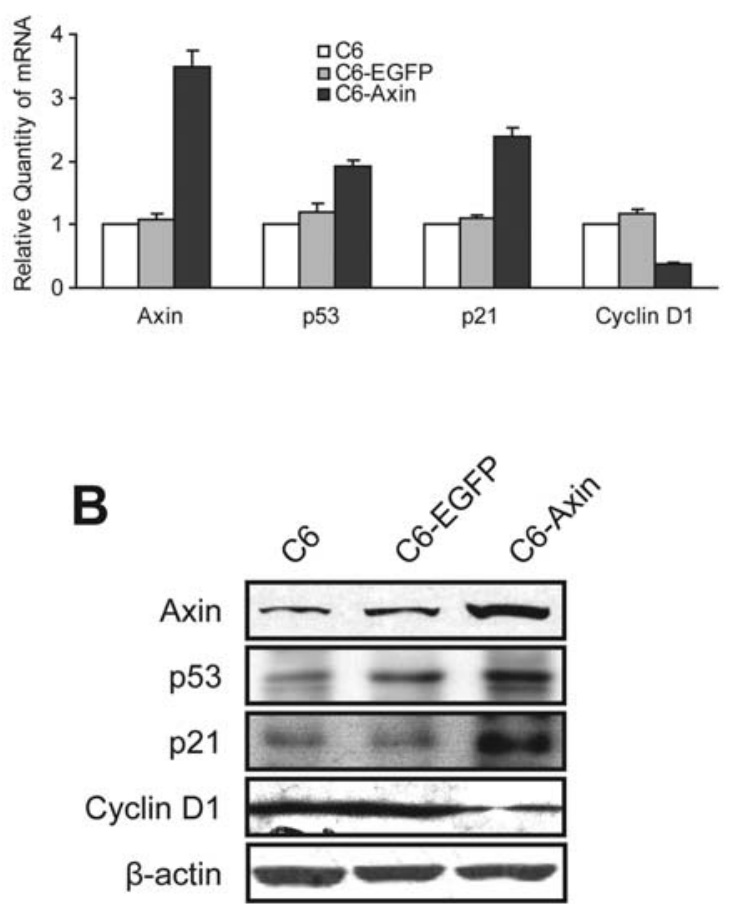

Figure 4. Protein and mRNA levels of Axin, p53, p21, and Cyclin D1 in C6 cells transfected with Axin. (A) The mRNA levels were measured by semiquantitative real-time PCR. The relative expressions of Axin, p53, and p21 mRNA were enhanced, and Cyclin D1 was reduced in C6 cells transfected with pIRES2-EGFP-Axin (C6-Axin) compared to the C6 cells transfected with pIRES2-EGFP (C6-EGFP). (B) The protein expression of Axin, p53, and p21 enhanced, and Cyclin D1 protein was reduced in C6-Axin cells compared to C6-EGFP cells.

Immunoblotting and real-time PCR were using to evaluate the protein and mRNA level of p53, p21 and Cyclin D1. As shown in the Fig. 4A, the mRNA level of p53 in C6 cells with overexpressed Axin markedly increased compared with the C6 cells transfected with pIRES2-EGFP $(\mathrm{P}<0.05)$. Moreover, the mRNA level of p21 was significantly increased $(\mathrm{P}<0.05)$, and the Cyclin D1 mRNA decreased $(\mathrm{P}<0.05)$ compared with the control groups. Similarly, the immunoblotting analysis revealed that Axin induced the expression of p53 and p21 in C6 cells, and reduced the expression of Cyclin D1 (Fig. 4B). These results suggested that Axin could activate the expression of p53, and then upregulate the p21 expression and downregulate the Cyclin D1.

To further investigate the role of p53 in the Axin-induced apoptosis and inhibition of cell growth, pifithrin- $\alpha$, which is a reversible inhibitor of p53-mediated apoptosis and p53dependent gene transcription, was used to treat the cells. The protein levels of Axin, p53 and its downstream genes were evaluated by immunoblot analysis. We found that the C6 cells with endogenous or overexpressed Axin treated with p53 inhibitor resulted in significantly reduction of p53 and p21, and induction of Cyclin D1 compared with C6 cells with overexpressed Axin (Fig. 5A and B), suggesting the p53 inhibitor could counteract the effect of Axin.

Furthermore, the effect of p53 inhibitor on the apoptosis induced by Axin was investigated using TUNEL staining.
A

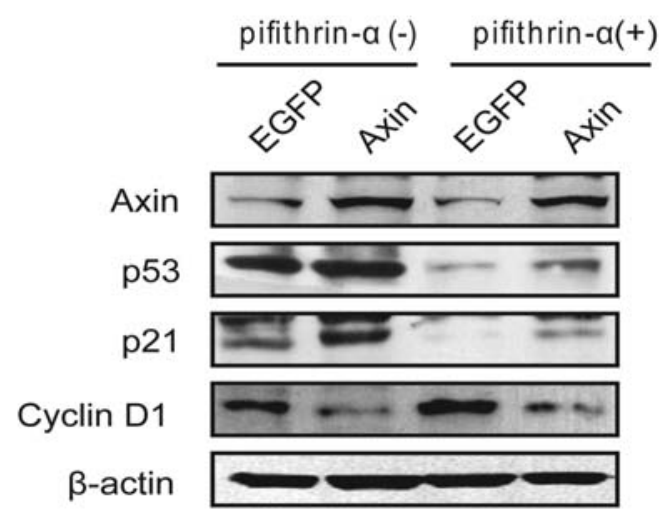

B

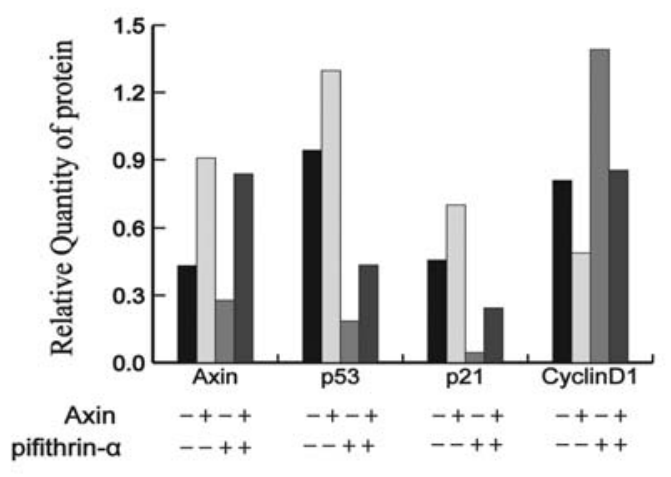

C

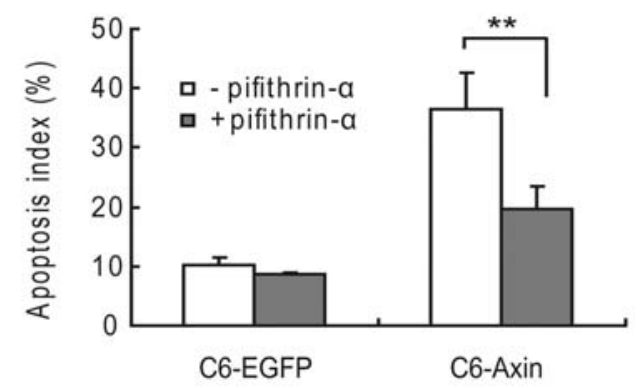

Figure 5. The p53 pathway plays an important role in Axin induced cell death. (A) Expression of Axin, p53, p21, and Cyclin D1 were examined by immunobloting in C6 astrocytoma cells with or without overexpressed Axin. Cells treated with pifithrin- $\alpha$, a p53 inhibitor, resulted in significant reduction of p53 and p21, and induction of Cyclin D1 compared with nontreated cells. (B) The relative quantity of Axin, p53, p21 and Cyclin D1 protein was analyzed by Quantity One software. (C) The effect of pifithrin- $\alpha$ on the apoptosis induced by Axin was investigated. The apoptotic index of C6 with overexpressed Axin (C6-Axin) treated with pifithrin- $\alpha$ was $19.5 \%$, and was decreased nearly $50 \%$ compared with the non-treated group. $\mathrm{n}=3 ;{ }^{* *} \mathrm{P}<0.01$.

The apoptotic index of C6-Axin treated with p53 inhibitor was $19.5 \%$, and nearly 2-fold lower compared to the non-treated group (Fig. 5C), suggesting the p53 inhibitor could antagonize the cell death-inducing effect of Axin. Collectively, these results demonstrate that the $\mathrm{p} 53$ pathway plays an importrant role the apoptosis induced by Axin in astrocytoma.

\section{Discussion}

Axin was identified in 1997 by Zeng et al (4). Deregulation of Axin has been found in different forms of cancer. Nakajima 
et al (14) found that Axin expression correlated inversely with depth of invasion, lymph node metastasis, and lymphatic invasion and suggested that reduced Axin expression correlated with tumor progression of esophageal squamous cell carcinoma. Zhou and Gao (23) also concluded that reduced expression of Axin might play a pivotal role in the carcinogenesis and metastasis of oral squamous cell carcinoma. Xu et al (24) showed that reduced expression of Axin is common in lung cancer. In the present study, we confirmed that Axin expression was negatively correlated with the grades of astrocytoma. These results indicate that Axin plays an important role in the progression of astrocytoma, and the expression level of Axin may provide useful information for estimating malignancy of astrocytoma.

$\mathrm{Ki}-67$ is a useful marker of proliferative information (25). We detected the expression of Ki-67 in astrocytoma. The result showed that high-grade astrocytoma exhibited higher Ki-67 immunoreactivity compared to low-grade tumors, this result concurs with previous investigations (26-28). The result indicated that Axin expression was correlated negatively with Ki-67 immunoactivity.

To further investigate the role of Axin in astrocytoma, we introduced Axin into C6 astrocytoma cells and examined the changes of apoptosis and cell growth. The results showed that overexpression of Axin induce cell death, inhibit cell growth, and reduce the colony formation ability in C6 astrocytoma cells. Axin has been suggested to be a tumor suppressor for many reasons: Axin plays a central role in the control of the oncogenic protein B-catenin in Wnt signaling pathway (29); Satoh et al (30) and Hsu et al (31) also found that introduction of wild-type Axin into the cancer cells could lead to cell death; high levels of programmed cell death occurred in the thymus and spleen of transgenic animals overexpressing Axin (31). Moreover, Axin stimulates p53, facilitating p53-mediated transcriptional activity and apoptosis (11). Our study provided further evidence for Axin as a tumor suppressor.

We also investigated the effect of Axin on the expression of p53 and its downstream genes p21 and CylinD1, which are known to regulate apoptosis and cell cycle distribution (20-22). Our results revealed that Axin induced the mRNA and protein levels of p53 and p21, reduced the level of Cyclin D1, while Axin silencing reduced p53 and p21 expression. These effects were abolished by the p53 inhibitor pifithrin- $\alpha$. The present result suggest that Axin induces cell apoptosis and reduces the distribution of $\mathrm{G} 2 / \mathrm{M}+\mathrm{S}$-phase cells by the $\mathrm{p} 53$ pathway. To achieve the role of p53 in tumor suppression, activated p53 seems to trigger two separable, albeit not mutually exclusive pathways, one to induce p21 for cell cycle arrest (32) and the other to induce proapoptotic factors such as Bax and Puma (33-35). Rui et al (11) showed that Axin and HIPK2 may preferentially trigger the apoptosis pathway but not the G1 cell cycle arrest pathway. However, our present study showed that Axin induced p53 and p21 for cell cycle arrest in astrocytoma. Additional studies will be necessary to elucidate the Axin-induced p53 pathway for apoptosis in astrocytoma cells.

In conclusion, we report for the first time that the expression level of Axin was correlated with the progression of astrocytoma, as well as Ki-67 labeling index. Axin induced cell death and reduced cell proliferative activity. Moreover, we found Axin could induce the expression of p53 and its targeting gene of $\mathrm{p} 21$, and downregulated the expression of Cyclin D1. Interestingly, the specific p53 inhibitor, pifithrin- $\alpha$, counteracted the cell-death-inducing and cell proliferation effect. Our data suggest that Axin induced apoptosis and inhibited cell proliferation in astrocytoma partially by activating the p53 pathway. Our finding will expand the avenues to understand the functions of Axin and p53 as both a tumor suppressor and a developmental regulator. In particular, induction of Axin overexpression has the potential to be developed into a future treatment for astrocytoma patients.

\section{Acknowledgements}

This work was supported by the State Key Laboratory of Cancer Biology grant, China (CBSKL 2005004 to Q.L.) and the National Natural Science Foundation of China (30671087 to Q.L. and 30700268 to J.Y.). We are grateful to Dr Rui Liu for help in statistical analysis, to Dr Shengcai Lin (Xiamen University) for providing Axin antibody and vectors, and to members in Qing Li's laboratories for technical assistance and helpful discussion. We also thank Dr Zhe Wang for his critical comments on the manuscript.

\section{References}

1. Louis DN: A molecular genetic model of astrocytoma histopathology. Brain Pathol 7: 755-764, 1997.

2. Baeza N, Masuoka J, Kleihues P and Ohgaki H: AXIN1 mutations but not deletions in cerebellar medulloblastomas. Oncogene 22: 632-636, 2003.

3. Collins VP: Genetic alterations in gliomas. J Neurooncol 24: 37-38, 1995.

4. Zeng L, Fagotto F, Zhang T, et al: The mouse Fused locus encodes Axin, an inhibitor of the Wnt signaling pathway that regulates embryonic axis formation. Cell 90: 181-192, 1997.

5. Kikuchi A: Roles of Axin in the Wnt signalling pathway. Cell Signal 11: 777-788, 1999.

6. Luo W and Lin SC: Axin: a master scaffold for multiple signaling pathways. Neurosignals 13: 99-113, 2004.

7. Luo W, Ng WW, Jin LH, Ye Z, Han J and Lin SC: Axin utilizes distinct regions for competitive MEKK1 and MEKK4 binding and JNK activation. J Biol Chem 278: 37451-37458, 2003.

8. Ikeda S, Kishida M, Matsuura Y, Usui H and Kikuchi A: GSK3beta-dependent phos-phorylation of adenomatous polyposis coli gene product can be modulated by beta-catenin and protein phosphatase 2A complexed with axin. Oncogene 19: 537-545, 2000.

9. Kishida S, Yomamato H, Ikeda S, Kishida M, Sakamoto I, Koyama S and Kikuchi A: Axin, a negative regulator of the Wnt signaling pathway, directly interacts with adenomatous polyposis coli and regulates the stabilization of beta-catenin. J Biol Chem 273: 10823-10826, 1998.

10. Zhang Y, Neo SY, Wang X, Han J and Lin SC: Axin forms a complex with MEKK1 and activates c-Jun NH(2)-terminal kinase/stress-activated protein kinase through domains distinct from Wnt signaling. J Biol Chem 274: 35247-35254, 1999.

11. Rui Y, Xu Z, Lin S, et al: Axin stimulates p53 functions by activation of HIPK2 kinase through multimeric complex formation. EMBO J 23: 4583-4594, 2004.

12. Li Q, Wang X, Wu X, et al: Daxx cooperates with the Axin/ HIPK2/p53 complex to induce cell death. Cancer Res 67: 66-74, 2007.

13. Lin SC and Li Q: Axin bridges Daxx to p53. Cell Res 17: 301302, 2007

14. Nakajima M, Fukuchi M, Miyazaki T, Masuda N, Kato H and Kuwano H: Reduced expression of Axin correlates with tumour progression of oesophageal squamous cell carcinoma. Br J Cancer 88: 1734-1739, 2003. 
15. Neo SY, Zhang Y, Yaw LP, Li P and Lin SC: Axin-induced apoptosis depends on the extent of its JNK activation and its ability to down-regulate beta-catenin levels. Biochem Biophys Res Commun 272: 144-150, 2000.

16. Li Q, Zhang XQ, Nie L, et al: Expression of interferon-gamma in human adrenal gland and kidney tumours. Br J Cancer 97: 420-425, 2007.

17. Liu S, Fang X, Hall H, et al: Homozygous deletion of glycogen synthase kinase 3 beta bypasses senescence allowing Ras transformation of primary murine fibroblasts. Proc Natl Acad Sci USA 105: 5248-5253, 2008.

18. Zhang LY, Li Q, Chen GS, et al: [Construction of the eukaryotic expression vector pIRES2-EGFP-Axin and its expression in glioma cells]. Xi Bao Yu Fen Zi Mian Yi Xue Za Zhi 21: 408-410, 2005

19. Pfaffl MW: A new mathematical model for relative quantification in real-time RT-PCR. Nucleic Acids Res 29: e45, 2001.

20. Van Lookeren Campagne M and Gill R: Tumor-suppressor p53 is expressed in proliferating and newly formed neurons of the embryonic and postnatal rat brain: comparison with expression of the cell cycle regulators $\mathrm{p} 21^{\text {Waf1/Cip1 }}$, p2 $7^{\mathrm{Kip} 1}$, p5 $7^{\mathrm{Kip} 2}, \mathrm{p} 16^{\mathrm{INK} 4 \mathrm{a}}$ cyclin G1, and the proto-oncogene Bax. J Comp Neurol 397: $181-198,1998$

21. Sherr CJ: Cancer cell cycles. Science 274: 1672-1677, 1996

22. Ismail IA, Kang KS, Lee HA, Kim JW and Sohn YK: Genistein-induced neuronal apoptosis and G2/M cell cycle arrest is associated with MDC1 up-regulation and PLK1 downregulation. Eur J Pharmacol 575: 12-20, 2007.

23. Zhou CX and Gao Y: Frequent genetic alterations and reduced expression of the Axin1 gene in oral squamous cell carcinoma: involvement in tumor progression and metastasis. Oncol Rep 17: 73-79, 2007.

24. Xu HT, Wei Q, Liu Y, et al: Overexpression of axin downregulates TCF-4 and inhibits the development of lung cancer. Ann Surg Oncol 14: 3251-3259, 2007.
25. Tortosa A, Vinolas N, Villa S, et al: Prognostic implication of clinical, radiologic, and pathologic features in patients with anaplastic gliomas. Cancer 97: 1063-1071, 2003.

26. Castellani P, Borsi L, Carnemolla B, et al: Differentiation between high- and low-grade astrocytoma using a human recombinant antibody to the extra domain-B of fibronectin. Am J Pathol 161: 1695-1700, 2002.

27. Zolota V, Tsamandas AC, Aroukatos P, et al: Expression of cell cycle inhibitors p21, p27, p14 and p16 in gliomas. Correlation with classic prognostic factors and patients' outcome. Neuropathology 28: 35-42, 2008.

28. Mao Y, Zhou L, Zhu W, et al: Proliferative status of tumor stem cells may be correlated with malignancy grade of human astrocytomas. Front Biosci 12: 2252-2259, 2007.

29. Liu C, Li Y, Semenov M, et al: Control of beta-catenin phosphorylation/degradation by a dual-kinase mechanism. Cell 108: 837-847, 2002.

30. Satoh S, Daigo Y, Furukawa Y, et al: AXIN1 mutations in hepatocellular carcinomas, and growth suppression in cancer cells by virus-mediated transfer of AXIN1. Nat Genet 24: 245-250, 2000

31. Hsu W, Shakya R and Costantini F: Impaired mammary gland and lymphoid development caused by inducible expression of Axin in transgenic mice. J Cell Biol 155: 1055-1064, 2001.

32. El-Deiry WS, Tokino T, Velculescu VE, et al: WAF1, a potential mediator of p53 tumor suppression. Cell 75: 817-825, 1993.

33. Miyashita T and Reed JC: Tumor suppressor p53 is a direct transcriptional activator of the human bax gene. Cell 80: 293-299, 1995.

34. Adachi S, Jigami T, Yasui T, et al: Role of a BCL9-related betacatenin-binding protein, B9L, in tumorigenesis induced by aberrant activation of Wnt signaling. Cancer Res 64: 8496-8501, 2004.

35. Attardi LD and DePinho RA: Conquering the complexity of p53. Nat Genet 36: 7-8, 2004. 